\title{
Evidence for the Absence of Worker Behavioral Subcastes in the Sociobiologically Primitive Australian Ant Nothomyrmecia macrops Clark (Hymenoptera: Formicidae: Myrmeciinae)
}

\author{
Robert W. Taylor ${ }^{1,2}$ \\ ${ }^{1}$ ARC Center of Excellence in Vision Science, Research School of Biology, The Australian National University, \\ Canberra, ACT 0200, Australia \\ ${ }^{2}$ CSIRO Ecosystem Sciences, Canberra, ACT 0200, Australia \\ Correspondence should be addressed to Robert W. Taylor; bob.taylor@homemail.com.au
}

Received 27 November 2013; Revised 2 March 2014; Accepted 20 May 2014; Published 18 June 2014

Academic Editor: Jacques Hubert Charles Delabie

Copyright (C) 2014 Robert W. Taylor. This is an open access article distributed under the Creative Commons Attribution License, which permits unrestricted use, distribution, and reproduction in any medium, provided the original work is properly cited.

\begin{abstract}
Activity in three colonies of the nocturnally foraging Australian ant Nothomyrmecia macrops is investigated. Workers apprehended while foraging were marked, released, and later recaptured within nests following excavation. Every forager in each nest was encountered and marked. It was expected that unmarked, nonforaging, domestic-specialist workers would be discovered in the nests. This was unexpectedly not the case as all workers, apart from one or two in each colony, had been marked, and therefore had foraged at least once during the three-night experiment. The few unmarked individuals are considered to have been temporarily residential nest-entrance guards. Behavioral subcastes comprising "domestic" versus "foraging" workers were thus not indicated, evidencing absence of worker caste polyethism in Nothomyrmecia. The experiment predated emergence in the nests of adult workers from cocoon-enclosed pupae at a season when large feeding larvae of the current annual brood were still being provisioned by foragers. Because Nothomyrmecia is univoltine and emergence of current-brood adults had not yet occurred, all workers present were from preceding annual broods and defined as "postjuvenile." A previous laboratory study separately evidenced absence of polyethism in Nothomyrmecia. Relevance of the apparent absence of food sharing in N. macrops is discussed.
\end{abstract}

Dedicated to the memory of Roger Bartell (1940-1985) esteemed friend and colleague in much Nothomyrmecia field work

\section{Introduction}

Following evolution of the gyne/queen and worker castes in ants, task specialization (division of labor or polyethism) among workers would likely early have involved distinction between (1) intranidal domestic functions and (2) extranidal food-collecting activities. This could encourage situations where workers operated either as domestics or as foragers, (1) intermittently, (2) in age-based succession, or (3) in either role essentially for life (thus comprising two behavioral subcastes exemplifying caste polyethism) (see [1-5]).

The experiment reviewed here investigated the relativities of intranidal versus extranidal activity among workers in three colonies of the Australian endemic Dinosaur Ant
Nothomyrmecia macrops Clark (subfamily Myrmeciinae), seeking to determine whether or not dedicated domestic versus specialist foraging subcastes were differentiated among Nothomyrmecia workers. The negative alternative was clearly evidenced.

Phylogenetically N. macrops is a member of the myrmeciomorph group of subfamilies in the formicoid clade $[6,7]$. It appears to have retained many behavioural and sociobiological traits considered ancestral for ants as a whole $[8,9]$, and it lacks many of the sociobiologically advanced features known in other ants $[8,9]$.

The absence of caste polyethism has been previously reported in only one other ant species, the "sociobiologically 
primitive" Stigmatomma pallipes (Haldeman) (Amblyoponinae) [10] (discussed there as Amblyopone pallipes, nomenclature here follows Yoshimura and Fisher [11]). Alternatively, the Nothomyrmecia-related, evidentially more sociobiologically derived, myrmeciines Myrmecia brevinoda Forel [12], and M. gulosa (Fabricius) have bimodally size-ranged polymorphic workers. In M. gulosa colonies the smallest workers associate with the queen, eggs and small larvae [13], and apparently never leave the nests [14 and pers. obs]. They appear to constitute a nest-bound non-foraging domestic worker sub-caste.

Most ants, including Nothomyrmecia, Myrmecia, and Stigmatomma, maintain perennial univoltine colonies [9]. In general, a single annual brood is reared from eggs laid by queens during a few weeks in spring. Development to adulthood takes around 12 months. The growing larvae are eventually overwintered and begin to pupate the following spring, about a year after oviposition, at around the time eggs of the next generation are being laid. Adult workers eclose from pupation (prior to escaping pupal cocoons in the above genera) during the late spring and summer, concluding at around the autumn equinox. For this reason the presence or absence and relative proportions of eggs, hatchling, and other small larvae, large larvae, and pupae vary seasonally, and there is a long autumn/winter period during which larvae of a single generation alone are present as brood in nests (and during which there is very little extranidal activity by workers, apparently because the larvae do not feed in winter, and prey collection is suspended [9]). Colonies in spring contain eggs and recently hatched small larvae of the latest generation, along with large previously overwintered old larvae and pupae of the preceding generation, with egg numbers declining as hatching proceeds and large-larval numbers reducing as pupation progresses. As the season advances workers begin to eclose and escape from their pupal cocoons, and all emerge by late summer or early autumn, leaving only part-grown larvae of the latest generation which are subsequently overwintered. These factors dictated the seasonal timing of the experiment described here.

Univoltinism results in recruitment of a single cohort of newly emerged workers each year during summer and early autumn, covering the time from beginning to end of eclosion of adults from pupation. Because of this, workers in mature colonies fall into discrete, usually morphologically unidentifiable, age-cohorts, each on average approximately one year younger than its predecessor. The number of worker generations present in any particular nest is determined by individual longevity and the age of the resident colony. Individuals of the earliest broods, including the first (initially laid down by queens at colony foundation), would often probably not survive to be represented in older colonies.

"Juvenile" Nothomyrmecia workers are defined here as adults under several months of posteclosion age, which are too young to have experienced the winter following their emergence versus "postjuvenile" adult workers, comprising older, previously overwintered, individuals surviving in colonies from former annual brood cohorts. Significance of the first overwintering experience involves the theoretical possibility that any (if any) polyethism among juvenile workers would possibly be lost during their first experience of winter colony dormancy, when foraging for prey by workers and behavioral acts related to eggs, actively feeding larvae or pupae are suspended.

The Nothomyrmecia colonies studied here were considered to be at least 3 or 4 years old (based on their worker numbers, and that their experimentally marked active nest entrances had been noted approximately one and two years previously). Whether their oldest workers were survivors from the initial founding brood is not known. All workers present, however, would have been postjuvenile and more than 10 or 11 months old, given that the current nearly mature $c a$ 1-year-old annual brood comprised large larvae and cocoon-enclosed pupae and had not yet produced (prospectively juvenile) adults. Two, three, or more annual age cohorts are estimated to have been represented.

The experiment was conducted in mid-November, 48-54 days after the vernal equinox, in Mallee Eucalyptus woodland at $85 \mathrm{~m}$ elevation, just south of Poochera, South Australia, about $600 \mathrm{~m}$ ESE of the Eyre Highway/Streaky Bay Road junction, at estimated coordinates $32^{\circ} 43^{\prime} 26.43^{\prime \prime} S$ and $134^{\circ} 50^{\prime} 21.78^{\prime \prime} \mathrm{E}$.

\section{Experimental Assumptions}

The following characteristics of Nothomyrmecia were assumed when designing the experiment or relate to discussion of its results. All have been repeatedly observed or experimentally demonstrated. (See also references $[8,9,15-17]$.)

(1) Nests function independently of each other and there is no morphological polymorphism among workers. (2) Each nest has a single, obscure entrance hole about $4-5 \mathrm{~mm}$ in diameter. (3) At all times, night and day, single guard workers may be observed inside nest entrances. They emerge briefly following insertion of a disturbing filament or a live ant of another species. (4) Foraging activity is strictly nocturnal. With the exception of assumption 11 below, Nothomyrmecia workers have never been observed naturally abroad in daylight. Departing foragers cross the ground promptly at dusk to ascend host trees on which they remain until returning directly across the ground at dawn to home nests. (5) Foragers depart nests en masse at dusk, emerging from the entrance, often partly queuing briefly in close single files, over a period of 10 to 20 minutes beginning at about the time they cease to be discernable by naked eye. (6) Each forager "headscans" on leaving the nest entrance, apparently confirming or recording visual navigational landmarks. The head, which is normally held parallel to the substrate, is pivoted slowly from side to side over an angle of about 80-100 degrees for up to 20 seconds while the ant stands otherwise motionless (often still partly within the nest entrance) with the antennal scapes held symmetrically, enclosing an angle of about 120 degrees. (7) Departing foragers disturbed experimentally near nest entrances after initial head scanning move away, rarely retreating back into the nest. (8) Prolonged uninterrupted liquid feeding for personal nutrition (terminated and presumably satiated by full crop distension) by foragers at 
interceptive diluted honey baits smeared experimentally on host tree trunks (Figure 2) does not suppress their behavioral drive to continue hunting for prey. Unless they eventually capture prey, these ants do not return to the nests until dawn. (9) Successful huntresses return to home nests during the night carrying the undissected prey in their jaws (Figure 3). (10) Unsuccessful huntress foragers return to nests at dawn. Their numbers usually greatly exceed those of previously returned successful foragers. The appearance of first-light apparently cancels their prey-getting drive, initiating nest return. Arrival at home nests is concentrated over 25-40 minutes from first light to approximately when the ants are faintly visible without artificial illumination. (11) Returnees failing to reach home nests before being overtaken by daylight secrete themselves in leaf litter near tree bases or groundlevel bark crevices. And presumably return eventually to their nests. (12) Nothomyrmecia queens leave nests to forage during colony foundation, probably up to the time when their first daughter workers appear. They are not known to exit the nests of worker-right colonies. (13) All adult ants are liquid feeders [9, pages 592-593]. Nothomyrmecia workers seek and imbibe appropriate nourishment while foraging outside the nests. Captured prey is returned to nests without dissection, largely as food for the carnivorous larvae (with some innest liquid feeding on hemolymph labiated from the remains of larval-dissected prey by workers and by the queen). (14) Nothomyrmecia workers do not lay chemical scent trails, and navigation is entirely visual.

\section{Experimental Procedure}

(1) Foraging workers departing an active Nothomyrmecia field nest were intercepted by covering the nest entrance with a large (ca. $190 \mathrm{~mm}$ dia., $20 \mathrm{~mm}$ deep) inverted clear glass evaporation dish (Figure 1). This was placed during the day and revisited after dark following accumulation under its cover of prospective foragers which had emerged from the nest entrance at dusk. (2) All detained ants were collected, carried together to a nearby field caravan, and promptly marked with single mesosomal or gastral paint spots of a single color (using diluted Tipp-Ex typists correction fluid) applied with a fine artists brush under a low-power stereomicroscope. Specimens were collected by aspiration and handled using soft spring-steel forceps. They were not anaesthetized or chilled. The marked ants were then promptly released as a group within $10 \mathrm{~cm}$ of the uncovered nest entrance. (3) After all had dispersed the cover dish was replaced over the nest entrance and checked regularly during the night and at dawn for returned foragers standing on its upturned base or at its periphery. Any previously marked returnees were replaced under the dish. The cover was removed in the morning after the last returnees had accumulated. Returnees without color spots were intercepted and color marked. (4) These procedures continued nightly until all ants seen on two successive dusk-to-dawn periods were observed to have been previously color marked. (5) The nest was then fully excavated and all resident ants collected. (6) The numbers of marked and unmarked ants were recorded. (7) The experiment was

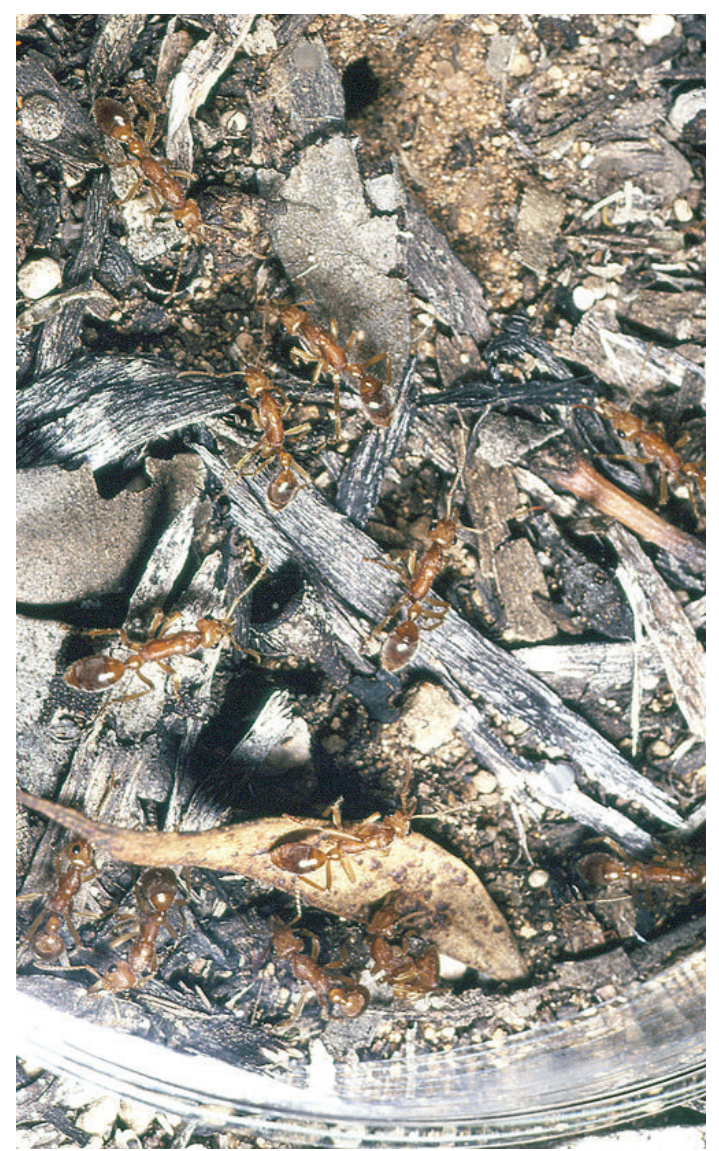

FIGURE 1: Nothomyrmecia macrops Clark: prospective foragers impounded at dusk under experimental cover dish prior to colour marking. The nest entrance is at the top of the picture (Poochera, SA, nest "yellow," R. W. Taylor).

simultaneously replicated on three adjacent colonies situated in a triangle with sides approximately $3 \mathrm{M}$ long; workers from each colony were separately distinguished by white, yellow, or green paint marks.

\section{Experimental Results}

(1) All ants replaced near nest entrances after marking promptly performed head scans and moved off to forage. None were observed to return immediately to their nests. (2) Morning-marking was required for only one forager returning at dawn on day 2 (colony "green"). It was presumably overlooked the previous evening or had secreted itself during the previous day after failed colony return. (3) The numbers of successful foragers returning with prey during the night were low: 2 for colonies "white" and "green" on night 1, 1 for colony "yellow" on night 1 , and 2 on night 2 (about 5.1\% of the total worker count). The great majority of returnees accumulated outside the covering dishes during the dawn return period without prey. (4) Single nest-entrance guards were observed in all colonies both by day and at night while the foragers were abroad. None were collected for color marking for fear of disrupting their behavior. (5) The marking 


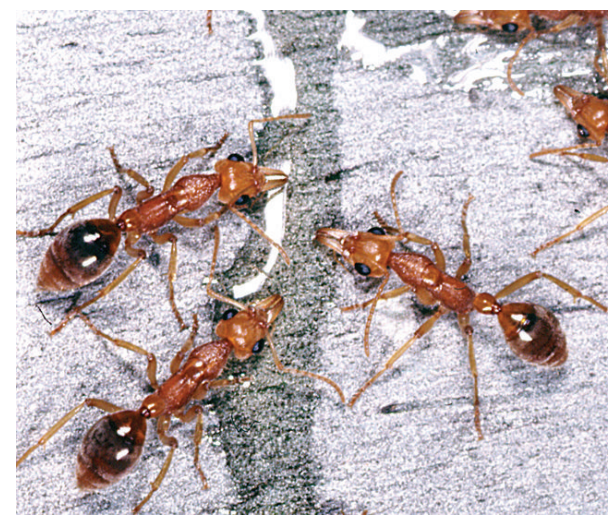

Figure 2: Nothomyrmecia macrops Clark: foraging workers feeding nocturnally at experimental honey bait on host Eucalyptus tree trunk. These ants accumulated as individuals, without collaborative interaction. Note the progressively distended gasters from right to left. (Poochera, SA, R. W. Taylor).

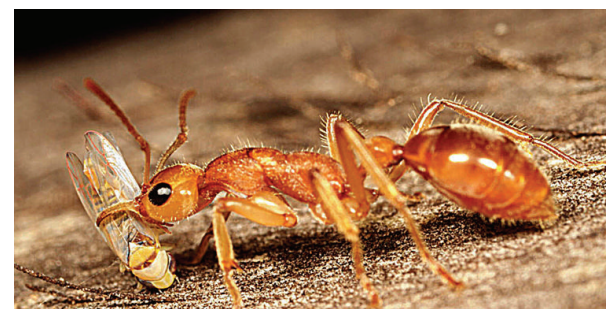

FIGURE 3: Nothomyrmecia macrops Clark: foraging worker with prey (male psyllid bug, Hemiptera: Psyllidae) (nocturnal, Poochera, SA, Ajay Narendra).

of workers was completed on night 3 for all three colonies. All those accumulated under the cover dishes at dusk or on their surfaces or surrounds at dawn on nights 4 and 5 were observed to have been previously marked, terminating the experiment. (6) The colonies were excavated and tallied on day 6. (7) The frequency of marked versus unmarked workers collected from each colony is given in Table 1. (8) All recovered colonies contained only one queen. All contained the appropriate seasonal brood of old, near fully grown larvae and congenerational cocoon-enclosed pupae of the current annual generation, with small, young larvae of the following year's cohort, destined to complete development to adulthood about 10-12 months later. There were no recognizable newly emerged callow workers or evidence (such as freshly cast pupal cocoons in nest middens) that eclosion had recently occurred. (9) No marked workers were recovered from nests other than those at which they were marked. (10) Queens were not observed to leave the nests.

If hard-wired caste polyethism was present in the subject colonies, dedicated domestic workers would not have departed the nests as foragers and would have been retrieved unmarked at excavation. This was not the case. The experimental results instead convincingly demonstrate that postjuvenile workers in mature, actively foraging field colonies of Nothomyrmecia macrops during the peak annual prey-getting season regularly engage in foraging and that any intranidal activity by individuals generally does not persist continuously for more than a few days before being interrupted by foraging. In the three nests (1) $41-50 \%$ of workers foraged on the first night; (2) $28-37 \%$ of workers first foraged after at least 1 night spent in the nest; (3) 13-25\% of workers first foraged after at least 2 nights spent in the nest. The consistency of results suggests that workers generally do not spend more than two nights in nests between foraging expeditions. During the three-night observation period 96-98\% left the nests to forage. The interception of previously marked workers on nights 2 and 3 indicates departures by individuals on successive nights. Four unmarked workers (2.9\% of the 137 in all 3 colonies) evidently did not leave the nests during 5 nights prior to excavation.

The unmarked workers were probably nest-entrance guards. The observed presence of guards during the experiment supports this conclusion. The assumption that guards are temporarily excused from foraging is tenable. Supporting evidence is provided by Jaisson et al. [16]. It is unlikely that these ants were foragers previously overlooked for marking or newly emerged juvenile workers not yet behaviorally programmed to forage. They might have been members of a queen retinue. The numbers indicate, however, that all but one or two workers of any such group present on day 1 must have foraged during the experiment (even assuming that the stayers were not guards or juveniles).

Experimental procedure prevented successful foragers from departing on a second same-night foray (they were inserted under the cover dish when apprehended in its vicinity with prey and so restricted to the nest for the remainder of the night). It is therefore not known if repeat foraging is practiced by Nothomyrmecia. By comparison, about $10 \%$ of individually numbered foragers of the phylogenetically related night-active bulldog ant Myrmecia pyriformis Smith have been reported to depart their nest repeatedly (usually twice, but up to 4 times in one individual) in a 1-night observation period [17].

In Nothomyrmecia (and Myrmecia pyriformis [17]) visual navigation across the ground between nest and host tree in dusk and dawn light is essentially crepuscular, and vision is probably less important than geotaxis for navigation on host trees during full darkness [15]. Nonetheless, nest return across the ground by prey-laden foragers in full nocturnal darkness clearly demonstrates capacity for visual navigation under such conditions. The Nothomyrmecia field program did not routinely record lunar phase, though for at least some nights of peak activity the Poochera site is clearly recalled to have been brightly moonlit. Future researchers should note this detail (see $[18,19])$.

The experiment would have been more informative if different sets of color marks had been used each night and foragers marked or remarked so as to record individual 5night foraging histories. Also, the entrance guards should perhaps have been extracted and marked with separate identifying colors.

Repetition of the experiment later in the season after emergence of juvenile workers would indicate whether there is a delay preceding foraging activity by juveniles after eclosion, because many more unmarked workers would then 
TABLE 1: The numbers of previously unmarked foraging workers departing 3 Nothomyrmecia macrops nests on 3 consecutive experimental nights, with the total numbers present in each nest as determined by a later excavation. Percentages are those of the full tallies for day 6.

\begin{tabular}{|c|c|c|c|}
\hline Colony & White & Yellow & Green \\
\hline Night 1 & $19(41.3 \%)$ & $26(50.0 \%)$ & $18(46.1 \%)$ \\
\hline Night 2 & 17 (37.9\%) & $18(34.6 \%)$ & $11(28.9 \%)$ \\
\hline Night 3 & $8(17.3 \%)$ & $7(13.4 \%)$ & $10(25.2 \%)$ \\
\hline Totals & $44(95.6 \%)$ & $51(98.0 \%)$ & $38(97.4 \%)$ \\
\hline Excavated (day 6) & $\begin{array}{c}46(44+2) \\
(100 \%)\end{array}$ & $\begin{array}{c}52(51+1) \\
(100 \%)\end{array}$ & $\begin{array}{c}39(38+1) \\
(100 \%)\end{array}$ \\
\hline
\end{tabular}

be expected to remain in the nests during the experimental period. If colonies were marked as described here prior to the eclosion season and excavated weeks later following the emergence of juveniles, marked postjuvenile and unmarked juvenile workers would be distinguishable. Similar use of a cover dish to intercept returning foragers could provide frequency estimates of successful versus unsuccessful preycollection departures and facilitate identification of prey organisms.

\section{Observation Nest Studies}

Social organization in two laboratory-based queen-right observation colonies of $N$. macrops with individually numbered workers was reported by Jaisson et al. [16].

The colonies were at approximately the same stage of annual brood cycle as those used in the field experiment discussed above, with a cohort of large larvae and pupae but no congenerational recently emerged workers, along with eggs and small larvae of a younger cohort. All workers must have been more than 10-11 months old.

Results demonstrated that (1) there is a strong tendency by the ants not to engage in social interaction (interactive acts were less than $1 \%$ of the 4,002 recorded) and (2) very few workers performed queen-directed acts. Some temporarily located near the queen more often than others, but were seldom in direct contact. "Their high co-presence indices....indicate...that they constitute a functional "royal retinue";" (3) worker polyethism was otherwise not apparent. Some individuals showed a propensity to guard the nest entrance. This activity "evidenced a high degree of specialization among its executors." Three workers performed as guards as well as foraging and caring for larvae in Colony 1, while one was involved at high frequency, and seven at very low frequency in Colony 2. None of the latter engaged in foraging, which in any case was relatively infrequent in colony 2; (4) exchange of food directly by trophallaxis or as trophic eggs was not observed between workers, workers and queen, or adults and larvae, apart from worker placement of intact, undissected prey near the larvae, which tore intersegmental membranes and dismembered prey carcasses by their own feeding activity; (5) the queen was observed to feed on hemolymph without assistance from workers, by licking larval-predissected prey; (6) there was no evidence of a dichotomy between dedicated domestic and foraging worker subcastes nor was there evidence in this study that workers specialized long term in performing particular innest activities, so it is reasonable to assume that this was also the case within the nests investigated in the field study reported here.

\section{Discussion and Conclusions}

All available evidence indicates that division of labor is likely absent in postjuvenile Nothomyrmecia macrops workers, apart from slight tendencies for one or two individuals at any one time to act as nest-entrance guards or several as members of a royal retinue. These acts are temporary and do not divert participants for long from other tasks including foraging and brood tending. Individual service in the queen retinue is short-lived judging from the laboratory study and field results in which so few workers remained in nests over the 5 subject nights.

Because their brood cycles antedated emergence of workers from cocoons, neither the field nor laboratory colonies discussed contained juvenile adult workers (as defined above). Future observation-nest investigation of juvenileworker-right colonies could facilitate recognition (or not) of behavioral differences among juveniles or between juveniles and postjuveniles and the possibility (or not) of identifying such behavior as hard-wired age-based temporal polyethism. Until this is investigated it cannot be affirmed that inherently programmed polyethism is absent among Nothomyrmecia workers, despite the evidence of this account and Jaisson et al. [16]. That is the reason why juvenile workers have been distinguished and defined here. Future researchers will need carefully to consider the findings of Traniello and associates $[1,2]$.

There is no evidence for intergenerational polyethism between workers of different annual brood cohorts, or among similarly aged workers of any single postjuvenile generational cohort nor, in the absence of anatomical polymorphism, is there any other evidence of caste polyethism among Nothomyrmecia workers.

The Stigmatomma pallipes colonies studied by Traniello [10] contained both juvenile and postjuvenile workers. The former, recognizable as relatively recently emerged callows, engaged in both brood-tending and foraging similarly to older (postjuvenile) noncallow individuals, except that they were not involved in egg care. Some individuals showed a degree of attachment to particular tasks, but this did not exclude them from other actions, and none of the acts 
under observation were significantly correlated. Traniello and Rosengaus [20] rightly point out that in these "primitive" ants "foraging is part of brood-care activity because larvae are directly provisioned with prey, and the same worker performs both tasks," and so it is with Nothomyrmecia. Nothomyrmecia workers operate almost entirely "in the manner of solitary insects" (to use Wilson's expression [4]). Alleged behaviorally programmed (as opposed to chance) interactions or cooperation between noncallow workers is extremely rare $[15,16]$. Interactions between Nothomyrmecia individuals are predominantly those between workers and brood [16]. It would be difficult to envisage less-collegial adult ants!

Exchange of food between workers, workers and queen, or adults and larvae by trophallaxis or as trophic eggs (as in Myrmecia [21, 22]) was not observed in Nothomyrmecia by Jaisson et al. [16] or by the author and others during many hours of focused or casual observation of laboratory colonies. Neither has larval hemolymph feeding been observed, as in Stigmatomma oregonense Wheeler [23] (cited there as Amblyopone oregonensis), a species close to S. pallipes. The ability secondarily to distribute nourishment therefore appears to be lacking in N. macrops, which presumably might never have evolutionarily acquired this capacity (secondary loss of such valuable behavior seems unlikely). This is evidently yet another "primitive" sociobiological characteristic of Nothomyrmecia. Workers, like queens, lick hemolymph from prey in nests following its dismemberment by feeding larvae. When foraging, they feed at experimental honey baits for up to 45 minutes while their gasters expand visibly due to crop distension (Figure 2). They normally lick carbohydraterich psyllid lerps, honeydew, and other sugary materials on leaves.

The specific need for workers to depart nests seeking liquid or soluble food for personal nourishment is exacerbated by the apparent absence of food-sharing behavior. Workers are known also to drink nocturnally at rainwater droplets accumulated in concave dry leaves lying on the ground (pers. obs.).

It could be argued that the prospect for further evolutionary sociobiological progression in $N$. macrops is compromised because food is not secondarily distributed within its colonies. For example, support of a domestic worker subcaste confined more-or-less permanently within nests might be functionally untenable, since its members might not receive adequate nourishment without personal foraging (though nest-bound queens clearly do survive and function effectively, apparently on prey hemolymph, perhaps on that alone in the apparent absence of food sharing). It is of interest that foraging workers, whatever their motivation for nest departure (whether personal hunger or stimulation by hungry larvae), engage in prey-hunting following personal satiation at experimental liquid-food baits. Thus, in terms of both personal feeding, and obtaining food for larvae, all departures are maximally utilized.

\section{Conflict of Interests}

The authors declare that there is no conflict of interests regarding the publication of this paper.

\section{Acknowledgments}

Philip Ward, James Traniello, Keiichi Masuko, Ajay Narendra, Jochen Zeil, David Yeates, and anonymous referees gave helpful advice.

\section{References}

[1] M. L. Muscedere, T. A. Willey, and J. F. A. Traniello, "Age and task efficiency in the ant Pheidole dentata: young minor workers are not specialist nurses," Animal Behaviour, vol. 77, no. 4, pp. 911-918, 2009.

[2] M. A. Seid and J. F. A. Traniello, "Age-related repertoire expansion and division of labor in Pheidole dentata (Hymenoptera: Formicidae): a new perspective on temporal polyethism and behavioral plasticity in ants," Behavioral Ecology and Sociobiology, vol. 60, no. 5, pp. 631-644, 2006.

[3] E. O. Wilson, "Behavioral discretization and the number of castes in an ant species," Behavioral Ecology and Sociobiology, vol. 1, no. 2, pp. 141-154, 1976.

[4] E. O. Wilson, "The sociogenesis of insect colonies," Science, vol. 228, no. 4707, pp. 1489-1495, 1985.

[5] E. O. Wilson, “The Principles of caste evolution," in Experimental Behavioral Ecology, B. Holl-dobler and M. Lindauer, Eds., pp. 307-324, Gustav Fischer, Stuttgart, Germany, 1985.

[6] P. S. Ward, "Phylogeny, classification, and species-level taxonomy of ants (Hymenoptera: Formicidae)," Zootaxa, no. 1668, pp. 549-563, 2007.

[7] C. S. Moreau, C. D. Bell, R. Vila, S. B. Archibald, and N. E. Pierce, "Phylogeny of the ants: diversification in the age of angiosperms," Science, vol. 312, no. 5770, pp. 101-104, 2006.

[8] R. W. Taylor, "Nothomyrmecia macrops: a living-fossil ant rediscovered," Science, vol. 201, no. 4360, pp. 979-985, 1978.

[9] R. W. Taylor, "Bloody funny wasps: speculations on the evolution of eusociality in ants," in Advances in Ant Systematics (Hymenoptera: Formicidae) Homage to E. O. Wilson: 50 Years of Contributions, R. R. Snelling, B. L. Fisher, and P. S. Ward, Eds., vol. 80, pp. 580-609, Memoirs of the American Entomological Institute, 2007.

[10] J. F. A. Traniello, "Caste in a primitive ant: absence of age polyethism in Amblyopone," Science, vol. 202, no. 4369, pp. 770$772,1978$.

[11] M. Yoshimura and B. L. Fisher, "A revision of male ants of the malagasy amblyoponinae (hymenoptera: Formicidae) with resurrections of the genera Stigmatomma and Xymmer," PLoS ONE, vol. 7, no. 3, Article ID e33325, 2012.

[12] S. Higashi and C. Peeters, "Worker polymorphism and nest structure in Myrmecia brevinoda Forel (Hymenoptera: Formicidae)," Journal of the Australian Entomological Society, vol. 29, pp. 327-331, 1990.

[13] V. Dietemann, B. Hölldobler, and C. Peeters, "Caste specialization and differentiation in reproductive potential in the phylogenetically primitive ant Myrmecia gulosa," Insectes Sociaux, vol. 49, no. 3, pp. 289-298, 2002.

[14] C. P. Haskins and E. F. Haskins, "Notes on the biology and social behaviour of the archaic ponerine ants of the genera Myrmecia and Promyrmecia," Annals of the Entomological Society of America, vol. 43, pp. 461-491, 1951.

[15] B. Hölldobler and R. W. Taylor, "A behavioral study of the primitive ant Nothomyrmecia macrops Clark," Insectes Sociaux, vol. 30, no. 4, pp. 384-401, 1983. 
[16] P. Jaisson, D. Fresneau, R. W. Taylor, and A. Lenoir, "Social organization in some primitive Australian ants. I. Nothomyrmecia macrops Clark," Insectes Sociaux, vol. 39, no. 4, pp. 425-438, 1992.

[17] S. F. Reid, A. Narendra, R. W. Taylor, and J. Zeil, "Foraging ecology of the night-active bull ant Myrmecia pyriformis," Australian Journal of Zoology, vol. 61, no. 2, pp. 170-177, 2013.

[18] A. Narendra, S. F. Reid, and J. M. Hemmi, "The twilight zone: ambient light levels trigger activity in primitive ants," Proceedings of the Royal Society B: Biological Sciences, vol. 277, no. 1687, pp. 1531-1538, 2010.

[19] N. Kronfeld-Schor, D. Dominoni, H. de la Iglesia et al., "Chronobiology by moonlight," Proceedings of the Royal Society B: Biological Sciences, vol. 280, no. 1765, 2013.

[20] J. F. A. Traniello and R. B. Rosengaus, "Ecology, evolution and division of labour in social insects," Animal Behaviour, vol. 52, pp. 209-213, 1997.

[21] C. P. Haskins and R. M. Whelden, "Note on the exchange of ingluvial food in the genus Myrmecia," Insectes Sociaux, vol. 1, no. 1, pp. 33-37, 1954.

[22] J. Freeland, "Biological and social patterns in the Australian bulldog ants of the genus Myrmecia," Australian Journal of Zoology, vol. 6, pp. 1-18, 1958.

[23] A. Wild, "Observations on larval cannibalism and other behaviors in a captive colony of Amblyopone oregonensis," Notes from the Underground, vol. 11, pp. 27-38, 2005. 

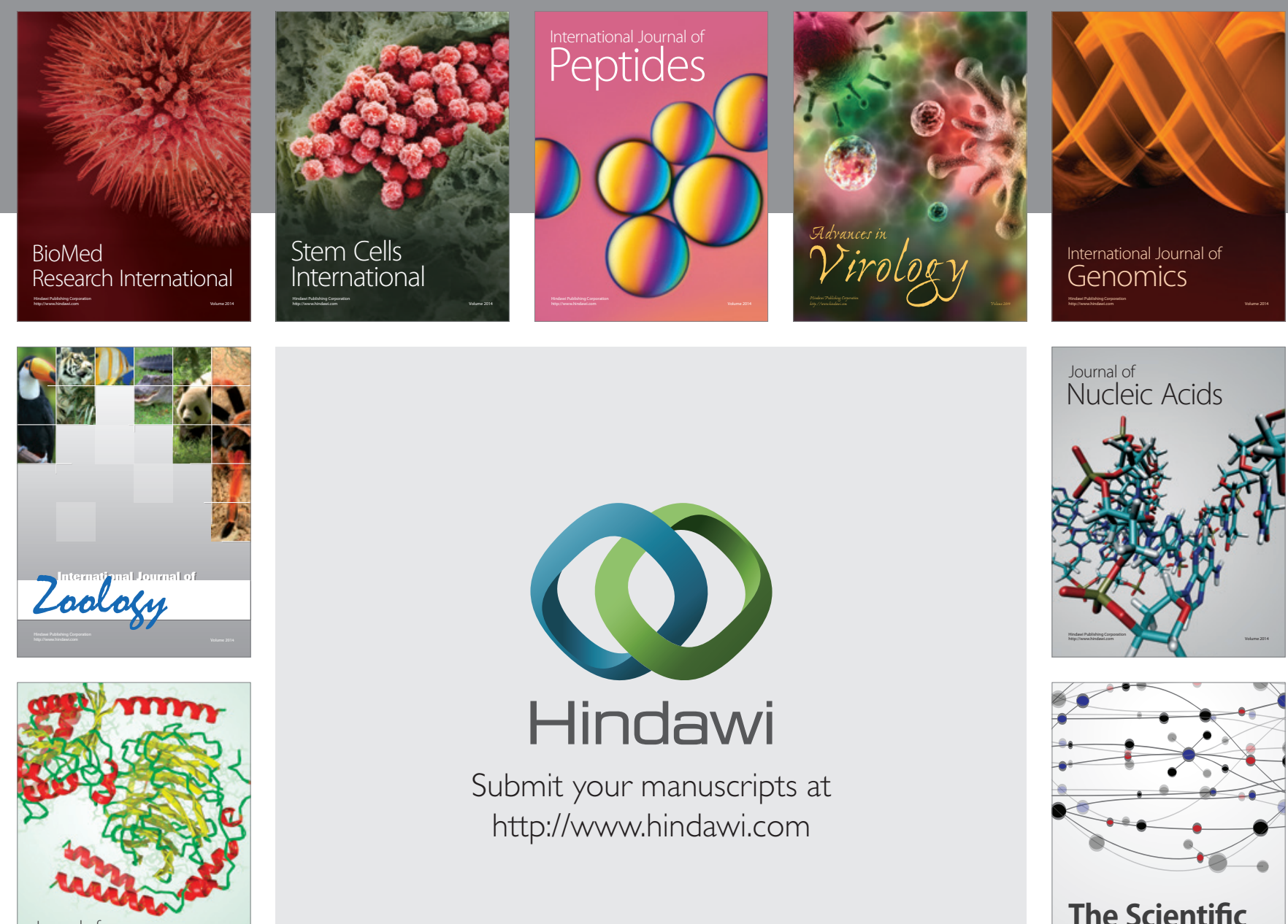

Submit your manuscripts at

http://www.hindawi.com

Journal of
Signal Transduction
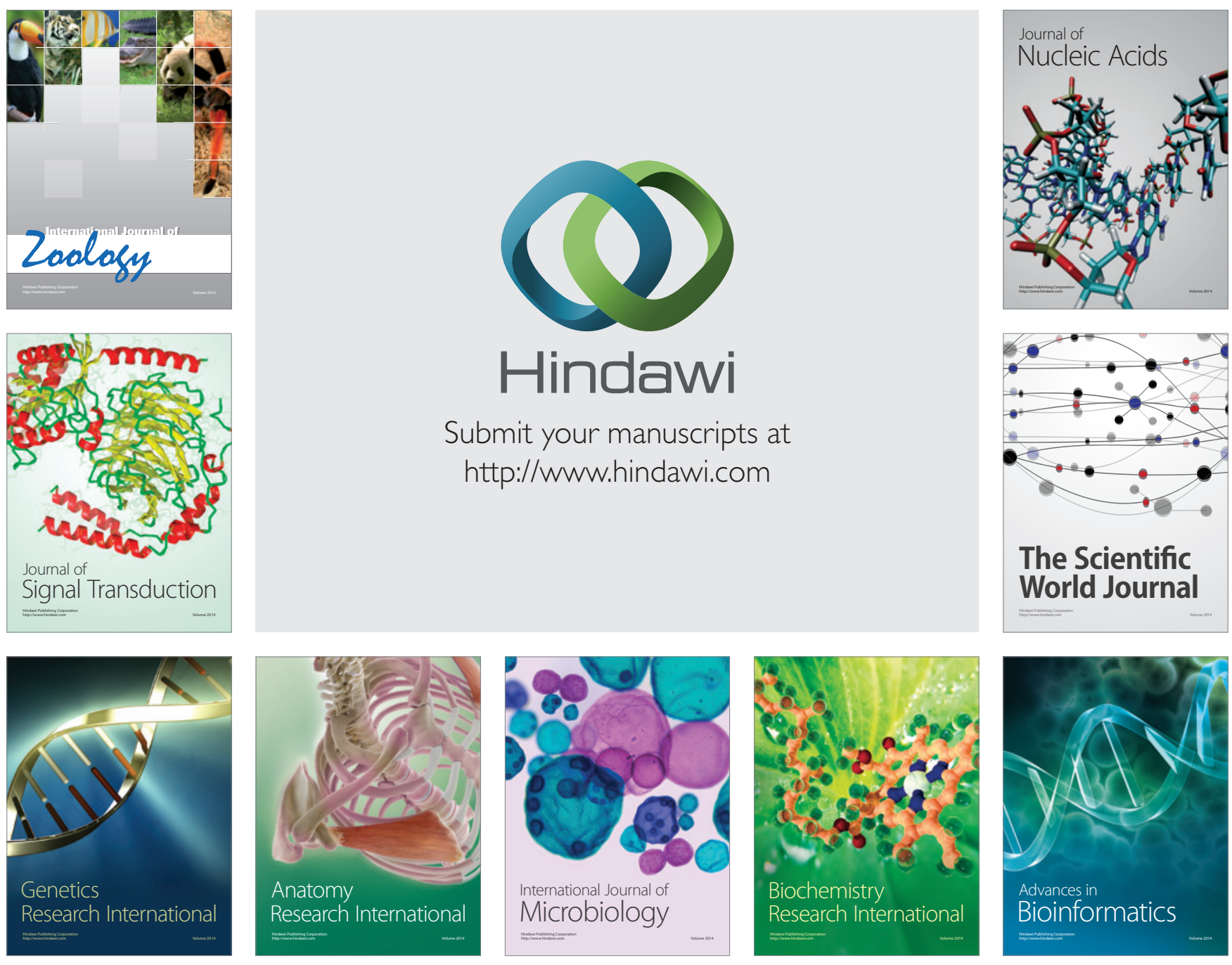

The Scientific World Journal
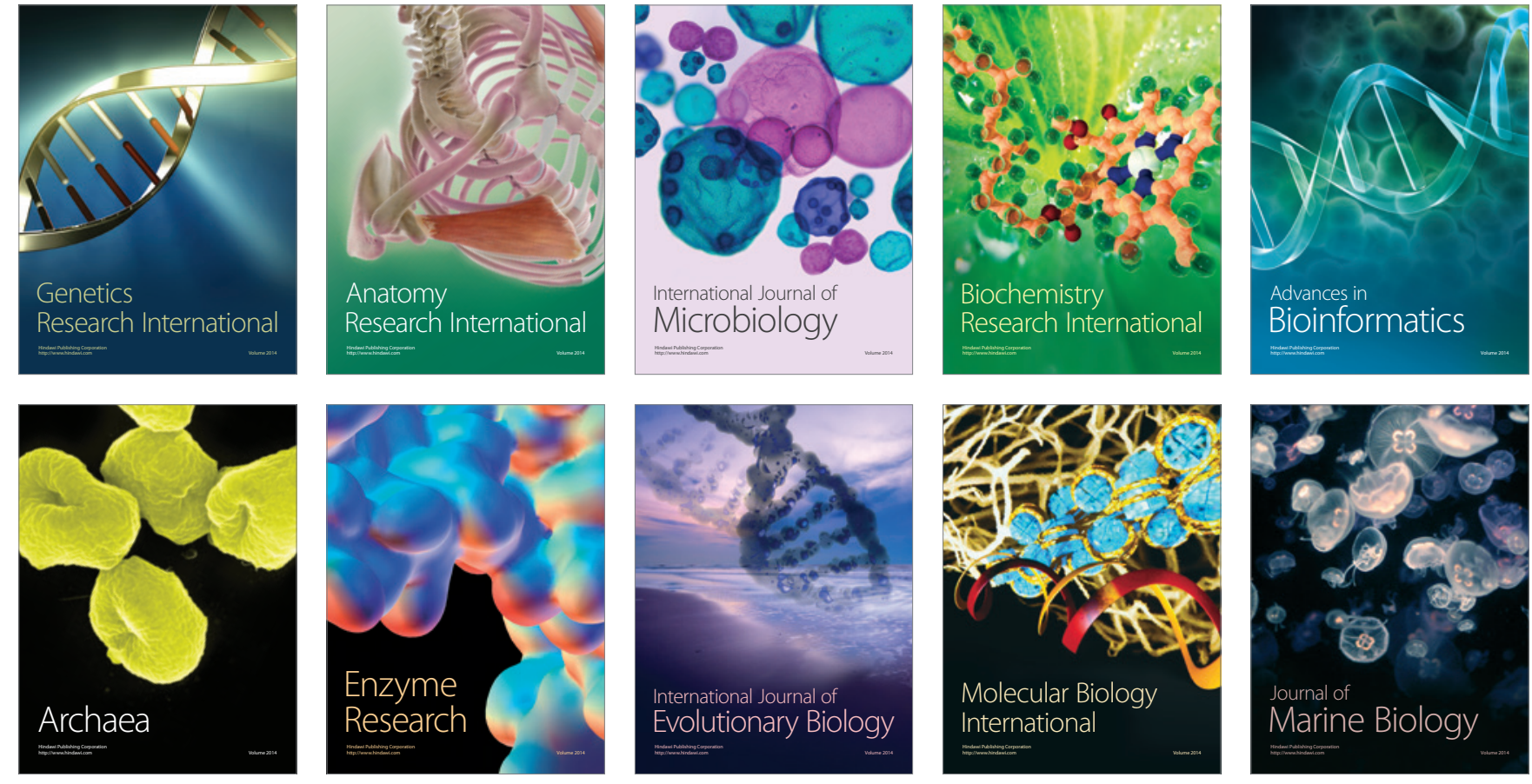